\title{
A Cross Sectional Study On Domain Based Evaluation Of Medical Students At The Tamil Nadu Dr.M.G.R.Medical University-A Success
}

\author{
Dr.Jhansi Charles, Dr.S.Kalpana, L.Joseph Stephen Max, Dr.D.Shantharam \\ The Tamil Nadu Dr.M.G.R.Medical University Guindy, Chennai,Tamil Nadu, India
}

\begin{abstract}
Aims and Objectives: To evaluate the levels of cognitive, psychomotor and affective domains in undergraduate, post graduates and super specialty medical students and to identify the domains in which the medical students need improvement.

Methods: Cross sectional study: The scores obtained in various methods of evaluation among 9551 under graduates, 657 Post graduates and 317 Super specialty medical students who underwent medical education in 2012 under the Tamil Nadu Dr.M.G.R.Medical University in various methods of evaluation were analysed in this study to determine their cognitive, affective and psychomotor domains and the scores they obtained were analysed in this study. The scores were compared to identify the deficient domains.

Results: In this study, it was noted that Grade II score (50-70\%marks) was obtained by majority of the students irrespective of the course they study while compared to grade I and Grade III. Among 9551 medical undergraduates, $16.8 \%$ were deficient in psychomotor domain and less than 10\% were deficient in other two domains and there was no association between domains and scoring marks. But in contrast, $15.4 \%$ post graduates were deficient in cognitive domain and $27.3 \%$ super specialties were deficient in affective domain .While comparing domains and scoring marks, significant association was noticed among post graduates ( $p$ value 0.000) and superspecialities ( $p$ value 0.002). Thus it was proved that undergraduates needed skills to improve psychomotor domain.
\end{abstract}

Conclusion: Undergraduates need skills to improve in psychomotor domain.

Key words: Cognitive, Psychomotor, Affective, domains.

\section{Introduction}

Evaluation of medical education in the affiliated medical colleges of any university is important to know whether the University has achieved the objectives and goals of the education programs prescribed by the university. In the medical education given by this university under study, evaluations are made by methods which involve mechanisms for determining the cognitive, affective and psychomotor domains of medical students. This evaluation helps us to provide feedback to the students on their progress or performance and to measure the effectiveness of teaching style, content of lesson and to succeed motivation in students. This study aims to analyse and compare the scores obtained by undergraduate, postgraduate and superspeciality medical students in these various evaluation methodologies and to identify the domains in which the medical students need improvement.

\section{Materials and methods}

This cross sectional study was done on Medical graduates, postgraduates and super specialities studied under the Tamil Nadu Dr.M.G.R.Medical University in the year 2012. Nearly 9551 Undergraduates, 657 post graduates and 317 Superspecialities underwent medical education in 2012. Their performance was determined by various evaluation techniques to determine Cognitive, Affective and Psychomotor domains. These techniques are a review of those with clear conclusion about their validity and reliability in the context of medical education. Cognitive domain was assessed by theory papers with long essays and short answer question for undergraduates and Theory papers, and dissertation for post graduates and super specialities. Affective domain was evaluated by viva voce for undergraduates, post graduates and super specialities. Psychomotor domain was evaluated by practical/clinical and OSCE/OSPE for undergraduates, postgraduates and super specialities. Students' performance was categorized in to three groups based on marks scored as follows: Grade I- above $70 \%$, Grade II - 51-70\% and Grade III - below 50\%.

\section{Statistical analysis}

All the data analysis was carried out using SPSS- ver 17. Results were expressed as frequency and percentage. Association between variables was assessed using chi-square. $\mathrm{p}$ value $<0.05$ was considered as statistically significant. 


\section{Results}

Out of 9551 medical under graduate students evaluated, $556(6 \%)$ students obtained grade I, 8234 $(86 \%)$ obtained grade II and $761(8 \%)$ obtained grade III in their theory exam which showed their level of cognitive domain. Similarly , 528(7\%) scored grade I, 7420(77\%) scored grade II and 1593(16\%) obtained grade III in their practical/clinical/OSCE/OSPE, determining their level of psychomotor domain. $815(9 \%)$ obtained grade I, 8001(83\%) obtained grade II and 735 (8\%) obtained grade III in viva voce, and this determined their affective domain. Statistically significant association was not observed using chi-square while comparing grading and domains among undergraduate medical students ( $p$ value 0.187 ) this is tabulated in table 1.

\begin{tabular}{|c|c|c|c|c|}
\hline Assessment method/Domain & $\begin{array}{l}\text { Grade I } \\
(>70 \% \text { marks })\end{array}$ & $\begin{array}{l}\text { Grade II } \\
\text { (50-70\% marks) }\end{array}$ & $\begin{array}{l}\text { Grade III } \\
<\mathbf{5 0 \%} \text { marks) }\end{array}$ & p-value \\
\hline $\begin{array}{l}\text { Cognitive } \\
\text { (Theory exam) }\end{array}$ & $556(6 \%)$ & $8234(86 \%)$ & $761(8 \%)$ & \multirow{3}{*}{0.187} \\
\hline $\begin{array}{l}\text { Psycomotor } \\
\text { (practical/clinical/OSCE/OSPE) }\end{array}$ & $528(6 \%)$ & $7420(77 \%)$ & $1593(16 \%)$ & \\
\hline $\begin{array}{l}\text { Affective } \\
\text { (Viva Voce) }\end{array}$ & $815(9 \%)$ & $8001(83 \%)$ & $735(8 \%)$ & \\
\hline
\end{tabular}

Table 1: Evaluation of undergraduate medical students ( $\mathrm{p}$ value $<0.05$ considered as statistically significant)

It is ascertained from the above table that Grade II was taken in all domains by most of the students. While comparing the Grade III scored in different domains by the students, it is obviously noted that more students scored less than fifty marks in psychomotor domain.

Out of 657 postgraduates, $31(5 \%)$ obtained grade I, 528(80\%) got grade II and 101(15\%) got grade III in theory examination showing their levels of cognitive domains. Similarly 28(4\%) got grade I, 589 (89\%) scored grade II and 40(7\%) got grade III in practical/clinical/OSCE/OSPE showing their levels of psychomotor domain. $127(19 \%)$ got grade I ,521(79\%) obtained grade II and $9(2 \%)$ got grade III in viva voce showing their levels of affective domain. More students showed Grade III in cognitive domain. Statistically significant association was observed while comparing grading and domains among postgraduate medical students ( $\mathrm{p}$ value $<0.050)$ This is tabulated in table 2.

\begin{tabular}{|l|l|l|l|l|}
\hline Assessment method/Domain & $\begin{array}{l}\text { Grade I } \\
(\mathbf{7 0 \%} \text { marks) }\end{array}$ & $\begin{array}{l}\text { Grade II } \\
\mathbf{( 5 0 - 7 0 \%} \text { marks) }\end{array}$ & $\begin{array}{l}\text { Grade III } \\
<\mathbf{5 0 \%} \text { marks) }\end{array}$ & p-value \\
\hline $\begin{array}{l}\text { Cognitive } \\
\text { (Theory exam) }\end{array}$ & $31(5 \%)$ & $528(80 \%)$ & $101(15 \%)$ & \\
\cline { 1 - 4 } Psycomotor (practical/clinical/OSCE/OSPE) & $28(4 \%)$ & $589(89 \%)$ & $40(6.9 \%)$ & 0.050 \\
\cline { 1 - 2 } & $127(19 \%)$ & $521(79 \%)$ & $9(2 \%)$ & \\
\hline
\end{tabular}

Table 2: Evaluation of postgraduate medical students ( $\mathrm{p}$ value $<0.05$ considered as statistically significant)

Out of 317 superspecialities, $27(8 \%)$ got grade I, $238(76 \%)$ got grade II. 52 got grade III (16\%) in theory showing their level of cognitive domain. Similarly $15(5 \%)$ got grade I. $216(68 \%)$ got grade II and 86 $(27 \%)$ got grade III in viva voce showing their levels of affective domain. Similarly $16(5 \%)$ got grade I, 282 $(89 \%)$ got grade II and $19(6 \%)$ got grade III in practical/ clinical/OSCE/OSPE showing their levels of psychomotor domain. More students showed grade III in affective domain. Statistically significant association was noted among super specialities while comparing domains and grades ( $p$ value 0.002) This is given in table: 3.

\begin{tabular}{|l|l|l|l|l|}
\hline Assessment method/Domain & $\begin{array}{l}\text { Grade I } \\
(>\mathbf{7 0} \% \text { marks) }\end{array}$ & $\begin{array}{l}\text { Grade II } \\
(\mathbf{5 0 - 7 0 \%} \text { marks) }\end{array}$ & $\begin{array}{l}\text { Grade II } \\
<\mathbf{5 0 \%} \text { marks) }\end{array}$ & p-value \\
\hline $\begin{array}{l}\text { Cognitive } \\
\text { (Theory exam) }\end{array}$ & $27(8 \%)$ & $238(76 \%)$ & $52(16 \%)$ & \multirow{2}{*}{0.002} \\
\cline { 1 - 3 } $\begin{array}{l}\text { Psycomotor } \\
\text { (practical/clinical/OSCE/OSPE) }\end{array}$ & $16(5 \%)$ & $282(89 \%)$ & $19(6 \%)$ & \\
\cline { 1 - 3 } $\begin{array}{l}\text { Affective } \\
\text { (Viva Voce) }\end{array}$ & $15(5 \%)$ & $216(68 \%)$ & $86(27 \%)$ & \\
\hline
\end{tabular}

Table 3: Evaluation of superspecialities ( $p$ value $<0.05$ considered as statistically significant)

From the above findings, it is noted that more number of undergraduate medical students scored grade III (less than 50\% marks) in clinical/practical/OSCE/OSPE showing that their psychomotor domain to be improved by skills in these exercises. Similarly more number of post graduates scored grade III in theory showing that their cognitive domain to be improved and more no of superspecialities scored grade III in viva voce showing that their affective domain to be improved. 


\section{Discussion}

This study was formulated to evaluate the various methods adopted by the university to determine the cognitive, psychomotor and affective domains of medical undergraduates, postgraduates and superspecialities who underwent medical education in this university. Since assessment drives education, it can be argued that all the assessment techniques identified as being currently used in medical education can be employed to assess critical thinking and reasoning in order to drive the educational goals of fostering and developing critical thinking in the medical graduates.

\section{Undergraduate Medical Stuents Performances}

Grade III scoring was taken by more number of undergraduates in clinical/practical exam which determined their psychomotor domain thus showing need for improvement of practical skills. Along with the present case studies, emphasis can be given to simulations, demonstrations, video demonstrations etc which are the skills needed to improve this domain as it was already explained by Nadia et al study [1]. High achievers as well as low achievers performed better in SAQ as compared to MCQ and MEQ. Instead of using single assessment tool multiple assessment tools should be used in definite proportion to assess the cognitive domain of UG medical students.[2] But in contrast, study done by Varun Kohli et al reported that the medical education unit of the institution could train faculty on appropriate teaching and assessment methods that might drive active learning[3]. Cinematic teaching methodology may be provided and movie scenes can be included to promote empathy because it reaches the learners' affective domain. [4] Multiple Choice Questions are easy to mark but very difficult to construct with high validity and fidelity especially at higher levels of cognitive assessment. [5,6] Structured Answer Questions and Long Essay Questions may be easier to develop at higher levels. However, studies have shown that testing at any level with SAQs and LEQs is fraught with the dangers of lack of construct validity both in the question and the key (known as item writing flaws) and inter - rater bias.[7] Oral examination too, when carefully administered may very well do the same with the added benefit of measuring communication skills both verbal and body language and general attitudes and behavior.[8-10]

Psychomotor skill need imitation,manipulation,precision,articulation and naturalization. As suggested in the national guidelines for educating GMS instructions to improve psychomotor skill, the students should be allowed to learn individual parts of skill during demonstrations. The students should be given ample time to practice a skill before being tested. There should be a constant direct supervision by the teachers. Make the students to prepare a skills check list for every practical/clinical exercises. Each practical/clinical session should end with a correct performances or demonstration of the skill.[31] Students OSEE performance video recordings, cardiac and pulmonary sounds audio recordings, electronic learning portfolios also can help the students to improve this skill.[32]The teaching learning method of integrated teaching improves the cognitive domain and makes positive attitude towards education.

\section{Post graduates Medical Students Performance}

Grade III scoring was taken by more number of postgraduates in theory exam which determined their cognitive domain showing the need for improvement in the preparation for writing theory exams .The postgraduates are now expected to answer 'reason out' questions in theory for which all topics need to be thoroughly read with understanding and concentration. Also, group discussions, seminars and journal clubs with detailed discussion about the topics are essential. Attending CMEs regularly is another way to update and clear the doubts. . Increasingly, students are being presented with problem - solving scenario in OSCE or its variants and in practical and clinical examinations. The use of reflective writing and its addition in assessment repertoire, $360^{\circ}$ evaluations, work-place and work - based evaluation, Mini - CEX exercises, peer and self assessment techniques, all increase the content in assessment of critical thinking, reflection and problem - solving.[11-18] Direct observation of clinical and practical skills, attitudes and behaviors using long and short cases, OSCE or any of its variants like TOACS and OSPE are indispensable tools of higher order skill and attitude measurement if applied correctly[19,20]. Long and Short cases can be standardized and made nearly as objective as OSCE[21-27].

\section{Super specialitity Medical Students Performance}

Grade III was obtained in viva voce in more number of superspecialities showing that these students should need skills to improve their affective domain. This can be improved by making them to serve as a coach for others who have habits of procrastination or to serve as a mentar for others as suggested by wendy-duncan Heartt et al.[28]. Also students should be encouraged to have more interaction during clinical hours because best learning occurs when there is active discussion as suggested in the final report 2014 by Sharan King et al[29]. As suggested by Gosling et al [30]. There should be changes in the teacher's conception and teaching: Offen from a teacher centered to a student centered perspective. 


\section{Conclusion}

Undergraduates were deficient in psychomotor domain, post graduates in cognitive domain and superspecialities in affective domain. Researchers suggest that the learning experience of medical students can be improved by structured and systematic clinical teaching; To improve the psychomotor skill, short frequent practice sessions over a long period of time, to improve physical practice and procedures like demonstrations, stimulations etc., to improve mental practice may be recommended. Faculties may be advised to plan clinical encounters keeping in mind a specific set of curricular objectives, rather than teaching opportunistically on whatever case comes along.

\section{References}

[2]. Nadia M Al-wardy, Assessment methods in undergraduate medical education, Sultan Qaboos Univ Med J. 2010 August; 10(2): 203-209.

[3]. Bodikha P, Effectiveness of MCQ,SAQ and MEQ in assessing cognitive domain among high and low achievers, IJRRMS, 2012,2(4).

[4]. Varun Kohli, Upreet Dhaliwal Medical students' perception of the educational environment in a medical college in India: a crosssectional study using the Dundee Ready Education Environment questionnaire J Educ Eval Health Prof 2013, 10: 5.

[5]. Pablo González Blasco et al Teaching Empathy through Movies: Reaching Learners' Affective domain in medical education, Journal of education and learning vol-1, 2012.

[6]. McLachlan JC, Whiten SC. Marks, scores and grades: scaling and aggregating student assessment outcomes. Med Edu. 2000; 34: 788-797.

[7]. Sargeant J, Eva KW, Armson H, Chesluk B, Dornan T, Holmboe E, et al. Features of assessment learners use to make informed self - assessments of clinical performance. Med Edu. 2011; 45: 636-647.

[8]. Edward JP, Paul D, Peter GD, Rohan R. The modified essay question: Its exit from the exit examination? Med Teach 2010; 32: e300-e307.

[9]. Brian DH, Shiphra G, Richard C, Sylvia C, Rhena D,Fred H, Ming - Jung H, Eric H, et al. Assessment of professionalism: Recommendations from the Ottawa 2010 Conference, Med Teach. 2011; 33: 354-363.

[10]. Gillian M, Janet S. Promoting professional knowledge, experiential learning and critical thinking for medical students, Med Edu. 2000; $34: 535-544$.

[11]. Fred T, Myrra VD, Anneke K, Richard G, Ben B. Behavioral elements of professionalism: Assessment of a fundamental concept in medical care, Med Teach. 2010; 32: e161-e169.

[12]. 11.Tracey P, Louise Y, Michele G, Michele H. An analysis of peer, self, and tutor assessment in problem - based learning tutorials, Med Teach. 2007; 29: e122- e132.

[13]. Patricia C, Audrey D, George S. Reflective ability and moral reasoning in final year medical students: A semi - qualitative cohort study, med teach. 2011; 33:e281-e289.

[14]. Sarah FG, Anja MB, Morten L. Triangulation of written assessments from patients, teachers and students Useful for students and teachers? Med Teach. 2010; 32: e552-e558.

[15]. Barbel P, Theresa W, Heather F, Elizabeth SD. Practice - based learning: views on the development of a reflective learning tool, Med Edu. 2000; 34: 754-761.

[16]. English R, Brookes ST, Avery K, Blazeby JM, Ben - Shlomo Y. The effectiveness and reliability of peer -marking in first - year medical students. Med Edu. 2006; 40: 965-972.

[17]. van der Vleuten CPM, Schuwirth LWT. Assessing professional competence: from methods to programmes. Med Edu.2005; 39: 309-317.

[18]. Magzoub MEMA, Schmidt HG. Ahmed A. Hameed A, Dolmans D, Mustafa SE. Student assessment in community settings: a comprehensive approach. Med Edu. 1998; 32: 50-59.

[19]. Wilkinson JR, Crossley JGM, Wragg A, Mills P, Cowan1 G, Wade W. Implementing workplace - based assessment across the medical specialties in the United Kingdom. Med Edu. 2008; 42: 364-373.

[20]. Ringsted C, Henriksen AH, Skaarup AM, Van der Vleuten CPM. Educational impact of in - training assessment (ITA) in postgraduate medical education: a qualitative study of an ITA programme in actual practice. Med Edu. 2004; 38: 767-777.

[21]. Spike N, Alexander H, Elliott S, Hazlett C, Kilminster S, Prideaux D, Roberts T. In - training assessment - its potential in enhancing clinical teaching. Med Edu. 2000; 34: 858-861.

[22]. Schuwirth LWT, Verheggen MM, van der Vleuten CPM, Boshuizen HPA, Dinant GJ. Do short cases elicit different thinking processes than factual knowledge questions do? Med Edu. 2001; 35: 348-356.

[23]. Hulsman RL, Mollema ED, Hoos AM, de Haes JCJM, Donnison - Speijer J D. Assessment of medical communication skills by computer: assessment method and student experiences. Med Edu. 2004; 38: 813-824.

[24]. Harden RM, Crosby J, Davis MH, Howie PW, Struthers AD. Task-based learning: the answer to integration and problem - based learning in the clinical years, Med Edu. 2000; 34: 391-397.

[25]. Farnill D, Hayes SC, Todisco J. Interviewing skills: self - evaluation by medical students. Med Edu.1997;31: 122-127.

[26]. Olson LG, Coughlan J, Rolfe I, Hensley MJ. The effect of a Structured Question Grid on the validity and perceived fairness of a medical long case assessment. Med Edu. 2000; 34: 46-52.

[27]. Norcini JJ. Current perspectives in assessment: the assessment of performance at work. Med Edu. 2005;39: 880-889.

[28]. Prescott LE, Norcini JJ, McKinlay P, Rennie JS. Facing the challenges of competency - based assessment of postgraduate dental training: Longitudinal Evaluation of Performance (LEP). Med Edu. 2002; 36: 92-97.

[29]. Wendy Duncan-Hewitt, Auburn University; Cy Leise, Bellevue University; and Ann Hall, Sinclair Community College: PACIFIC Crest- Faculty guide book. Affective domain 2012: 83-84

[30]. Sharon king, Christian voigt: Affective domain of tracing - Final report April 2013: 21-22

[31]. Gosling D(2001)"Educational development units in the UK: what are they doing five years on?" International Journal of Academic Development, 2001, 6, 74-90

[32]. National guidelines for educating EMS instructors,: Teaching psychomotor skills: August 2002, Module 17.

[33]. Recommendation for clinical skills curricula for undergraduate medical education by Association of American Medical Colleges, 2008. 